RUNNING HEAD: ROLES OF PUSH AND PULL IN LEAVING RELIGION

\author{
Examining Exit: The Roles of Push and Pull in Leaving Religion \\ Joel Engelman \\ Joshua Briggs Grubbs \\ Glen Milstein \\ Irvin Sam Schonfeld
}

Corresponding author:

Joel Engelman

Bowling Green State University

227 Psychology Building

Bowling Green, OH 43403

Email: jengelm@bgsu.edu 


\begin{abstract}
The population of religious "nones," those who do not affiliate with any religion, is continually growing. Many of those who identify as nones have exited from religious traditions. Sparse research has examined the psychological processes involved in religious exit. Although various theories of religious exit have been proposed, they have provided limited empirical utility for psychological research. Immigration psychology, with its empirically well-established paradigms, may provide a better theoretical basis with which to understand religious exit. More specifically, the push (from origin group) and pull (towards destination group) theory of migration may be useful in understanding what motivates individuals to leave religions, and the individual psychological experiences of the religious exit process. Further, the push and pull theory may inform the trajectories of disaffiliates and their psychological wellbeing and adjustment post religious exit. This study's main aim was to empirically establish a measure of push-pull forces for religious exit. To accomplish this goal, Latent Variable Modeling was performed to reduce a larger push-pull item bank (38 items) to a brief 8-item scale. Hypothesis testing using correlation and Structural Equation Modeling demonstrated that push and pull are associated with mental health outcomes for those leaving religions.
\end{abstract}

Keywords: nones, religious disaffiliation, religious switching, apostasy, migration 


\section{Examining Exit: The Roles of Push and Pull in Leaving Religion}

Religious exit is a growing phenomenon in the United States and in much of the Western world. In the U.S., since the 1970's, nationally representative studies have consistently demonstrated a large growth of the group defined as "nones," those who do not identify with any religion (Twenge, Sherman, Exline, \& Grubbs, 2016). Further, a large segment of nones report that they were raised within religious traditions from which they chose to disaffiliate in adulthood. For example, according to Pew’s 2015 American Religious Landscape Survey, a record high $22.8 \%$ of Americans identified as unaffiliated, while $78 \%$ of those individuals reported to have previously been part of a religion (Pew Research Center, 2015).

There has been little empirical work exploring psychological processes of religious exit and how those processes could affect individual psychological wellbeing (Fisher, 2017). For many exiting religions, especially those leaving defined religious groups, leaving may result in many tangible losses, including the loss of social and familial relationships and supports (Myers, 2017). It is therefore important that psychological processes involved in religious exit be further examined. The present work is poised to address this need through the validation of a measure of psychological processes involved in religious exit.

\section{Religious Disaffiliation and Wellbeing}

An abundance of research has identified that religion is often beneficial to individual health and wellbeing (Ellison, 1991; Sullivan, 2010), which may imply that exiting religion could come at a certain cost. Those disaffiliating from religious communities are likely to lose many of the beneficial aspects attributed to religion in regards to wellbeing, particularly the aspects of social support and community found within religious groups (Hui et al., 2018). Relatedly, if the disaffiliation is concurrent with a loss of meaning of life which was provided by religious group membership, the individual may have reduced coping skills to cope with life- 
stressors (Park, 2005). Negative outcomes of disaffiliation may be particularly salient for individuals leaving insular and or covenantal religious communities (Engelman et al., 2020). Disaffiliates from covenantal religious communities may be shunned and ostracized, even by members of their own family (Hookway \& Habibis, 2015; McGinnis, 2015). Additionally, disaffiliates from covenantal communities may endure material losses such as divorce, loss of employment, and loss of custody of children due to religious disaffiliation (Berger, 2014).

Despite the difficulties involved in religious disaffiliation, there may also be inherent gains for disaffiliates. Persevering through an intense and arduous experience, such as religious disaffiliation, may provide the disaffiliate with a sense of mastery and self-efficacy (Altemeyer \& Hunsberger, 1997), a newfound sense of autonomy (Davidman, 2014), and self-discovery (LeDrew, 2013). Finally, disaffiliates who felt that their social, emotional, or intellectual needs were not being met within their former religious groups, may find those needs met post religious exit (Hui et al., 2018).

Studies examining religious disaffiliation and wellbeing. There have been a handful of empirical studies examining the wellbeing of those who have disaffiliated from religious groups. Scheitle and Adamczyk (2010) found that those within demanding, "high cost" religions have better self-reported health than those within other religious traditions, however, those leaving demanding religions reported worse health than those leaving non-high-cost religions. Comparing the health and subjective wellbeing of disaffiliates from several religious denominations, Fenelon and Danielsen (2016) found that ex-Evangelical Protestants and exCatholics reported the lowest subjective wellbeing, and those who left high-cost religious groups reported the lowest health. Additionally, they found that the reduced subjective wellbeing present within disaffiliate groups improved over time. In a three-year prospective study, Hui et al. (2018) examined the psychological changes of Chinese Protestant disaffiliates and found that 
approximately half had improved psychological functioning and the other half had decreased psychological functioning post-disaffiliation. Poor quality of life at baseline was a risk factor for decreased psychological functioning post-disaffiliation.

\section{Religious Switching}

In contrast to those who leave religious groups and disaffiliate from organized religion altogether, many individuals switch from one religious group to another (Stark \& Glock, 1970). Hoge et al. (1995) identified four reasons for religious switching: 1) due to interfaith marriage; 2) due to geographic relocation; 3) due to dissatisfaction with one's own church; 4) due to personal ties and influences from another church. Much of the research literature has found that those who switch between religious groups are often more intrinsically religious than those who stay within their religious groups, especially those who leave because of dissatisfaction of their church (Hadaway \& Marler, 1993). A reason for this phenomenon is that switching religions requires more effort and commitment than staying within a religious denomination (Hoge et al., 1995).

However, others have found that some who switch religious groups are looking for a more liberal denomination (Sherkat \& Wilson, 1995). Sparse research has directly examined the psychological characteristics of those who switch religions as compared to those who disaffiliate from religions, and therefore further inquiry is necessary.

\section{Migration Theory and Religious Exit}

A number of theories have been employed in studies on religious exit. Bahr (1970) used disengagement theory to explain why aging individuals disaffiliate from religion, arguing that aging individuals mutually disengage from society at large, which includes religious disaffiliation. Brinkerhoff and Burke (1980) used labeling theory to argue that disaffiliates were labeled and marginalized within their former religious communities, which served as a catalyst for their disaffiliation. Hunsberger (1983) used social learning theory, arguing that disaffiliates 
observed decreased religious commitment by their parents, which influenced their disaffiliation. Ebaugh (1988) studied Catholic nuns who had left the church using role theory to understand the processes of switching roles from being a nun with a defined role identity to a person without a defined role identity. Brinkerhoff and Mackie (1993) used a career typology in which they categorized different types of religious leavers into a "religious careers typology." Bromley (1998) used organizational exit theory to delineate different exit roles for disaffiliates. Anderton et al. (2011) examined the religious identity conflicts of queer individuals, using cognitive dissonance theory, they analyzed how the dissonance experienced by those individuals could lead to religious disaffiliation. The theories listed above have generally only been applied to specific populations, and they have not been used to understand religious exit as a broad phenomenon.

Further, although theories used in past research may be informative to understanding specific aspects of religious exit, well-established migration theories may offer broader insights with regards to motivations for religious exit and the psychological sequelae post-exit. Religious disaffiliation, especially from covenantal and insular religious groups, may be understood as an immigration (Bahr \& Albrecht, 1989; Berger, 2014). Immigration psychology has an established framework of the processes that compel the would-be migrant to leave their origin community (Moon, 1995).

\section{Push and Pull}

The push-pull framework has been lauded as one of the most important theoretical contributions to the migration literature (Jackson, 1986). Through an economic approach to migration, the theory of push-pull posits that would-be migrants are driven by both, aspects of being pulled towards the destination community, and aspects of being pushed from their origin community (Klein et al., 2009; Rauhut, 2011). The push variable is generally described as the 
elements that compel the future-migrant from within their country of origin, for instance, because of violence or lack of resources that are debilitating to their thriving. The pull variable are those elements that are attractive to the future-migrant elsewhere outside of their country of origin, for instance, plentiful resources and opportunity in another location. A way to illustrate the difference between push and pull is to consider the differing motivations of the refugee who is pushed to leave their origin community, in contrast to the economic migrant who is pulled towards economic opportunities in a new locale. Due to a yet undeveloped theoretical framework of religious exit, the theoretical frameworks that have been used to study religious exit do not offer the parsimonious coherence and empirical applicability that the well-established paradigms within the study of immigration such as the push-pull framework can provide. The push-pull framework can be constructive in understanding why individuals switch between religions or why they choose to become irreligious altogether. Further, the push-pull paradigm may offer a predictive framework in regards to psychological wellbeing post-religious exit.

Within the migration literature, push is generally found as a negative force with regards to satisfaction with life (Amit, 2010), immigrant integration (Doerschler, 2006), and general wellbeing post-immigration. In contrast, pull has often been demonstrated as a positive force regarding those same wellbeing factors. In a previous study examining the process of disaffiliation from Orthodox Judaism, Engelman et al. (2020) used the push-pull immigration paradigm to predict individual disaffiliate wellbeing through their process of disaffiliation. Findings from the study included that higher levels of being pushed from origin community was predictive of increased loneliness, lower psychological and emotional wellness, and lower overall health post disaffiliation, even when effects of personality were controlled. The study also demonstrated that the push-pull framework may be useful in understanding religious disaffiliation. 


\section{Group Insularity and Cost of Leaving}

Researchers using the push-pull framework have noted that additional factors within the process of migration should be considered. Based on the work of Longino Jr (1992), Moon (1995) introduced a third factor, moorings, in addition to push and pull. Moorings encompass the individual's consideration of their subjective cultural, spatial, and lifestyle values in comparison to how those aspects of life would be realized in the destination society (Chang et al., 2014). As such, moorings are personal and social factors that could hinder, or alternatively, encourage, the individual to migrate (Bansal et al., 2005). In the context of switching behaviors, moorings have been described as the costs of switching that are to be considered by the individual who is contemplating the switch (Chang et al., 2014). In terms of religious exit then we can consider mooring factors such as the costs of leaving the specific religious group, which include the level of insularity of said group, as leaving an increasingly insular group would mean overcoming a larger acculturation curve when joining outside society. The disaffiliating individual must consider these mooring cost factors in their decision to leave, which may hinder or encourage their leaving, in addition to the push and pull factors that are compelling them to disaffiliate. It is likely then that these mooring factors could impact the forces of push and pull, and additionally, may impact the disaffiliates wellbeing post-disaffiliation.

\section{Current Study}

In light of the above reviewed literature, it was expected that an adaptation of the pushpull model of immigration may be of utility in understanding religious exit, and this study sought to validate a push-pull measure for religious exit. Further, this study explored the predictive value of the push-pull framework for religious disaffiliates and switchers with regards to psychological wellbeing. 
This study sought to validate the push-pull measure using a diverse sample of individuals who have disaffiliated or switched from several religious groups. Using factor analyses, we sought to demonstrate that push-pull is a psychometrically sound construct for religious exit. Further, using bivariate correlations and Structural Equation Modeling, we sought to demonstrate that push and pull, as distinct but related variables, are both correlated and predictive of mental health outcomes. Finally, by controlling for group insularity we sought to demonstrate that the push-pull construct is particularly salient for those leaving insular religious groups.

Given the above, we expected that when performing a factor analysis using the push-pull item bank from a previous study (Engelman, et al., 2020), we would find a two-factor solution reflecting both push and pull as relevant factors in religious exit. Further, we expected that disaffiliates and switchers from religious groups that reported higher costs of leaving would also report increased levels of push. We reasoned that given the high costs to exit from those groups, disaffiliates and switchers would likely have been motivated to exit by experiences of being pushed by others from within the group, resulting in the option of leaving the group to be a more desirable one, despite the inherent costs. We also expected that those who reported higher levels of push would be less involved with their former religious groups post-disaffiliation. Since push experiences are interpersonal by nature, it seemed likely that the disaffiliate or switcher who experienced higher levels of push would be less likely to want to associate with individuals from their former religious groups. Further, we expected that higher levels of push would be associated with reduced psychological wellbeing. Push experiences, such as being the victim of shunning or social rejection by the religious group, are emotionally impactful, and would likely negatively affect mental and emotional wellbeing. Finally, we expected that higher levels of pull would be associated with increased psychological adjustment for religious disaffiliates and switchers. Being that pull experiences are generally towards attractive elements outside of the 
origin community, it seemed likely that the disaffiliate or switcher driven by pull experiences and who was able to partake in those attractive aspects of life post-disaffiliation, would have increased psychological adjustment.

\section{Methods}

\section{Participants}

A total of 1,126 participants were recruited through snowball sampling methods via postings on various social media websites, list-serves, and online groups of religious disaffiliates. Online support communities for ex-evangelical Christians, ex-Muslims, ex-Jews, ex-Mormons, ex-Jehovah's Witnesses, and ex-Catholics were specifically targeted, though the survey was distributed through a range of other communities. Distributions included Facebook, Twitter, Reddit, and various email lists. The participants were directed to an online survey questionnaire where they were presented with a series of measures and demographic questions. Participants who reported that they have exited a religious group at some point in their lives were presented the entire questionnaire. Those who reported that they had not exited a religious group, were barred from completing the survey. For the purposes of this study, only those participants who completed all relevant measures $(n=842)$ are included in the analysis. Demographic information for this sample is provided in Table 1.

\section{Measures}

Push-pull. Owing to the lack of established measures to test the push and pull dimensions of religious exit, original measures for each dimension were created by Engelman et al. (2020). A group of individuals who had disaffiliated from Orthodox Jewish communities provided feedback and input on the items. Exploratory factor analysis further guided the placement of the items into their respective push-pull dimensions. The Cronbach's alpha coefficients demonstrated sufficient reliability within the initial sample; pull measure $(\alpha=.92)$, 
push measure $(\alpha=.86)$. All scale items used a seven-point Likert scale $(1$, strongly disagree to 7 , strongly agree). The pull items were designed to assess aspects of the outside, secular world that were attractive to the disaffiliate. The items spanned opportunities outside of the religious community such as more autonomy, increased religious participation, access to the arts and education, and diverse moral attitudes. Example items included, "I wanted to leave my former religious community so that I could dress to my liking," and "some lifestyles outside the community seemed more moral to me." One original pull item was removed, and three additional pull items were added for this data collection. The push items assessed aspects within religious communities that could have motivated disaffiliates to leave. The items span conditions that were distressing to the participant, such as familial dysfunction, abuse, and shunning. Example items included, "I wanted to leave my religious community to get away from dysfunctional surroundings," and "I experienced physical harm while in my religious community." An additional push item, "I was pushed out by forces within from my former religious community," was added for this data collection.

Group insularity. We designed a 16-item measure to assess the level of insularity of the participant's former religious group. The measure examined geographical insularity, behavioral insularity, and social insularity. The items included, "in life within my former religious community: the majority of people I interacted with on a daily basis were fellow community members." All items used a 5-point Likert scale (1, strongly disagree to 5, strongly agree).

Cost of disaffiliation. We designed an 8-item measure to assess for the participant's religious groups warnings of the perceived costs of disaffiliation. The items included "I was told that if I left my former religious community: I would be officially excommunicated." All items used a 6-point Likert scale (0, does not apply to 5, strongly agree). 
Connectedness with former religious group. We designed a 7-item measure to assess for the participant's continued tethering to their former religious group post-disaffiliation. The measure consists of items regarding the participant's regret of leaving their religious group, such as "How often have you wished you had stayed in your religious community," and items regarding the participant's ongoing social interaction with members from their former religious group such as, "How often have you spent time with members still in that religious community," within the past twelve months. All items used an 8-point scale (from 0-never to 7-once a day or more).

Religious importance. We assessed the importance of religion in one's life with items adapted from the Religious Beliefs Salience Scale (Blaine \& Crocker, 1995). The 5-item measure asks participants to respond to items such as "Being a religious/spiritual person is important to me," on a scale of 0 (strongly disagree) to 10 (strongly agree).

Life satisfaction. Participants were presented with the Satisfaction with Life Scale (SWLS) (Diener, Emmons, Larsen, \& Griffin, 1985), which measures global life satisfaction. The SWLS has demonstrated consistent internal and discriminant validity, as well as convergent validity with other measures of subjective wellbeing (Pavot et al., 1991). The scale has additionally demonstrated a degree of temporal stability dependent on stability of subjective wellbeing within the individual's life (Pavot \& Diener, 1993). The scale has also been independently validated with many diverse samples. The scale consists of five items using a seven-point Likert scale (1, strongly agree to 7, strongly disagree).

Life meaning. We assessed for presence of life meaning with the Meaning in Life Questionnaire (MILQ) (Steger, 2004). The 10-item MILQ assesses for both the presence of and the search for life meaning (Steger et al., 2010). The MILQ has demonstrated sufficient 
reliability, as well as convergent, discriminatory, and incremental validity (Steger, 2004). All items use a 7-point Likert scale (1, absolutely untrue to 7, absolutely true).

Depression and anxiety. We used the DSM-5 Self-Rated Cross-Cutting Symptom Measure - Adult to assess for symptoms associated with psychopathology (American Psychiatric Association, 2013). The measure has demonstrated utility as a screener for psychopathology (Clarke \& Kuhl, 2014). Response options to the items are measured on a 5-point Likert scale (none $=0$, slight $=1$, mild $=2$, moderate $=3$, severe $=4$ ). A composite score using the depression and anxiety dimensions of the scale was calculated to assess those symptoms within this study's sample.

Neuroticism. We used the Neuroticism facet score from the IPIP-NEO-60 (MaplesKeller et al., 2017) to measure neuroticism. The overall measure has demonstrated sufficient reliability and convergent validity with other more extended measures of personality. All items use a 5-point Likert scale (1, disagree strongly to 5, strongly agree).

Time since leaving. Participants were requested to provide the number of years since their most recent religious exit or switch between religions.

\section{Analysis}

To validate and shorten the Push-Pull measure, we performed a hybridized Exploratory Factor Analysis (EFA) and Confirmatory Factor Analysis (CFA). In the first step, given the size of the Push Pull item bank (28 Pull items and 10 Push items), we sought to reduce the item bank by approximately forty percent. Using a theoretical approach, we selected ten items for the Pull factor and four items for the Push factor which best captured their respective theoretical concepts. The items were placed in a CFA using robust diagonally weighted least squares estimation, with a specific goal of reducing the included fourteen items to a parsimonious, balanced scale. The model with the fourteen items demonstrated an unsatisfactory fit $\left(\chi^{2}(72)=\right.$ 
268.0, $p<.001$, comparative fit index $[\mathrm{CFI}]=.957$, root mean standard error of approximation $[\mathrm{RMSEA}]=.053$, standardized root mean square residual $[\mathrm{SRMR}]=.036)$, as the residual covariances among items was too high and the scale was imbalanced. We then used the resulting modification indices and factor loadings of the CFA to create a balanced scale and reduced the scale to a total of eight items (four Pull items, four Push items; fit indices reported below).

Further, we examined Pearson product moment correlations with regards to the scores on our cost of disaffiliation and push and pull scales, the scores on our connectedness with former religious group and push and pull scales, push and pull scores and the DSM-5 Self-Rated CrossCutting Symptom Measure depression and anxiety scores, and the push and pull scores and the score of the Satisfaction with Life measure and the Presence score from the Meaning in Life Questionnaire, signifying psychological adjustment.

To explore the relationships between Push, Pull, psychological pathology, and psychological adjustment, we conducted two Structural Equation Models (SEM). Each model examined the paths of the latent variables of Push and Pull (indicated by the items of each subscale) towards the outcome/endogenous variable, as well as the paths of the observed exogenous variables of Time since leaving, Neuroticism (using the Neuroticism score on the IPIP-NEO-60), Insularity of the religious group from which the individual disaffiliated, and Religious Belief Salience as they related to the outcome variable, and to the latent variables of Push and Pull. In the first SEM (see Figure 1), the endogenous observed variable of Depression and Anxiety, using a composite score from the DSM-5 Self-Rated Cross-Cutting Symptom Measure - Adult, was designated as the outcome variable. In the second SEM (see Figure 2), the observed variable of Satisfaction with Life, using the scores obtained from the Satisfaction with Life Scale, was designated as one of two endogenous outcome variables, and the observed variable of the presence of Life Meaning, using the score obtained from the "presence" dimension of the 
Meaning in Life Questionnaire, was designated as the second of two outcome variables in the model.

\section{Results}

Descriptive statistics for all included measures are provided in Table 2. The results of the analyses are provided below.

\section{Latent Variable Model}

The final push-pull items and their descriptive statistics are provided in Table 3 . The latent variable model and each item's factor loadings are provided in Figure 1. The latent variable model, using robust diagonally weighted least squares estimation, demonstrated adequate fit in the sample when robust statistics were used $\left(\chi^{2}(19)=73.262, p<.001, \mathrm{CFI}=\right.$ $.991, \mathrm{RMSEA}=.040, \mathrm{SRMR}=.035)$. Internal consistency coefficients (Cronbach's alpha and McDonald's omega) coefficients demonstrated acceptable reliability within the sample for the final items; push measure $(\alpha=.74, \omega=.74)$, pull measure $(\alpha=.67, \omega=.68)$.

\section{Bivariate Correlations}

The correlations of all predictor variables and dependent variables used in the study are provided in Table 4. With regards to our expectation that encountering higher costs of disaffiliation from a religious group would be associated with higher levels of Push, a significant positive correlation was found, $r=.50, p<.001$. With regards to our expectation that encountering higher levels of Push in the process of religious exit would be associated with reduced continued former religious group involvement, a significant negative correlation was found, $r=-.10, p<.001$.

Push and Pull were moderately correlated, $r=.54, p<.001$. Correlational analyses revealed small to moderate positive associations between Push and all respective RSS dimensions. In addition, correlations revealed small to moderate positive associations between 
Push and Neuroticism, former group Insularity, and Cost of Leaving. Further, push was negatively associated with Life Satisfaction. In regards to Pull, correlations revealed small to moderate positive associations between Pull and Neuroticism, Cost of Leaving, and former group Insularity.

\section{Structural Equation Modeling}

To explore the relationship between push-pull and psychological pathology, a structural equation model was conducted (see Figure 2). The model demonstrated adequate fit in the sample $\left(\chi^{2}(49)=209.423, p<.001\right.$, Robust: CFI $=.979$, RMSEA $=.047$, SRMR $\left.=.039\right)$. Neuroticism and Push were significantly positively related with depressive and anxious symptomology, and Time since religious exit was significantly negatively related with depressive and anxious symptomology.

To explore the relationship between push-pull and psychological adjustment, a structural equation model was conducted (see Figure 3). The model demonstrated adequate fit in the sample $\left(\chi^{2}(55)=202.666, p<.001\right.$, Robust: $\left.\mathrm{CFI}=.979, \mathrm{RMSEA}=.043, \mathrm{SRMR}=.037\right)$. Pull and Time since religious exit were significantly positively associated with Life Satisfaction, and Neuroticism and former religious group Insularity were significantly negatively associated with Life Satisfaction. As for the presence of Meaning In Life, Religious Belief Salience and Time since religious exit were significantly positively associated with Life Meaning, while Neuroticism was significantly negatively associated with Life Meaning.

In both structural equation models, the latent Push variable was significantly predicted by higher reported levels of former religious group Insularity, higher Neuroticism, and higher Religious Belief Salience. While the latent Pull variable was significantly predicted by higher levels of former religious group Insularity and Neuroticism. Pull was also significantly 
negatively associated with Time since religious exit. Standardized coefficients for all the above structural equation models are provided in Table 3.

\section{Discussion}

The purpose of this study was to validate a measure of the push and pull forces that may be present in religious exit. In service of that goal, a shortened measure from a large item bank of push-pull items was validated and created. Our results demonstrated that Push and Pull are related, but distinct, variables within the process of religious exit. Below, is a review of the findings and a discussion of the implications, limitations, and future directions of this research.

Using an exploratory latent variable modeling approach and confirmatory factor analyses, a two-factor solution was found within the push-pull item bank, and the measure was shortened to a total of eight items. The respective measures demonstrated acceptable internal consistency within the sample. Correlational analysis revealed that push was significantly positively correlated with costs of leaving. Additionally, correlational analyses revealed a small but statistically significant negative association between Push and continued former religious Group Involvement. Further, structural equation modeling revealed that, beyond Neuroticism, Push significantly explained unique variance predicting anxious and depressive symptomology. Finally, with regards to our expectation that higher levels of Pull would be associated with higher levels of psychological adjustment, was only partially fulfilled, as Pull was significantly predictive of Life Satisfaction, but was not predictive of Meaning in Life.

\section{Implications}

As has been demonstrated in the migration research literature, exploring the migrant's push and pull factors can be informative in understanding their decision to migrate, and those factors can additionally be predictive of post-migration individual wellbeing and integration into a new society. The results of this study seem to indicate that the push and pull factors can also be 
informative and predictive in the process of religious exit. More specifically, Push was strongly associated with mental health pathology for religious leavers post-exit. While Pull was associated with an indicator of greater psychological adjustment post religious exit.

Of note, our results indicate that, on average, religious disaffiliates and switchers do not experience high, much less clinical, levels of anxiety or depression, as mean levels on our composite measure derived from the DSM-5 Self Rated Cross-Cutting Symptom Measure were fairly low and below the measure's range midpoint $(M=1.40, S D=1.01)$.

The variable of Time since exit was included in all structural equation models and was predictive of increased psychological adjustment and decreased mental health symptomology over time. Higher levels of Time since exit also demonstrated a relationship with higher levels of Pull, which may indicate a recency effect.

Our results are consistent with previous research (Hout \& Fischer, 2014) with regards to religious leavers endorsing the pursuit of autonomy as a motivator for leaving religious groups. Two of the four final Pull items relate to the pursuit of autonomy. In particular, the item "I was drawn outside of my former religious community so that I could lead my own life, instead of following what I was told to do," received the highest endorsement $(M=5.52, S D=1.89)$ of any of the Push or Pull items.

With regards to another motivating factor for religious exit reported by Baker and Smith (2009), that having a close friend or family member who exited prior as an influence for religious exit, our results seem to both support and contradict this finding. The item "I was motivated to leave my community by others who had left before me" demonstrated internal consistency within the sample and is included as one of the final four Pull items. In contrast, the item, on average, received low endorsement $(M=2.90, S D=1.95)$. 
In regards to the finding by Brent (1994), that disaffiliates from fundamentalist religious groups live with ongoing emotional residue post disaffiliation, our findings seem to be consistent with this claim in regards to the insularity of one's former religious group. Although we did not measure for religious group fundamentalism, most fundamentalist religious groups have an element of insularity (Arce \& Sandler, 2009). In our findings, Insularity of former religious group demonstrated the strongest relationships with both Pull and Push. Further, Insularity of former religious group was associated with lower Life Satisfaction post-exit.

Our findings support previous findings with regards to religious belief being associated with increased meaning in life (Park, 2005). The variable of Religious Belief Salience -the importance placed in one's religious beliefs- was included in all structural equation models. Religious Belief Salience was associated with Life Meaning, while Pull was not.

\section{Limitations and Future Directions}

This study has several limitations. Firstly, the study's data were collected through retrospective self-report, which may better represent the study participant's current reasoning in regards to why they left a religious group, rather than the actual reasoning they had pre-religious exit. This may especially be true for those who left their religious groups many years prior to this study. Conversely, self-report measures can be valuable tools, particularly in regards to individual personal beliefs which may not be accessible through other methodologies (Chan, 2009). Secondly, due to this research's use of a cross-sectional single measurement design, our findings cannot suggest inferences of causality, particularly with regards to the directionality of the predictions in the structural equation models. Additionally, although our sample was diverse with regards to origin religious groups from which participants had exited, our sample cannot be considered representative of the larger population of those who leave religious groups, as the recruitment for this study specifically focused on religious disaffiliate groups with an accessible 
social media presence. An additional limitation may be that we included both religious switchers and religious disaffiliates in the study's analyses. Being that religious switchers may have endorsed Push and Pull items to a lesser degree than religious disaffiliates, this may have reduced the effects of Push and Pull within our analyses.

The final Pull and Push scales demonstrated somewhat marginal Cronbach's Alpha coefficients (Push $\alpha=.74$, Pull $\alpha=.67$ ). Given that the final scales consist of items which when presented to the study's participants were distant from each other within the order of the questionnaire items, this may have disrupted internal consistency to a degree. Although the scales demonstrated somewhat marginal internal consistency, given that structural equation modeling was used, we may rely on the results obtained, as SEM methodology is more precise than other regression methods, as SEM ostensibly removes measurement error and extraneous variance. That is, latent variables represent more cohesive phenomena than raw scores. Yet, this strength of SEM is also a weakness, as interpreting latent variables in real world settings is often quite challenging.

Considering the above limitations, future studies could improve on this work in several ways. Specifically, longitudinal studies could further explore lasting associations between Push, Pull, mental health outcomes, and possible interactions with time since leaving a religious group. Additionally, informed by migration literature, the bulk of this study focused on pre religious disaffiliation factors (Push, Pull) and post religious disaffiliation factors (mental health outcomes). Future studies should additionally focus on the disaffiliation process itself and how the experience of leaving a religious group may impact mental health and adjustment. One such direction may be the examination of whether successful or unsuccessful realization of an individual's expectations of the disaffiliation process may impact wellbeing. Finally, future 
studies are needed to further validate the Push Pull measure as put forth here by presenting only the finalized eight items to study participants.

\section{Conclusion}

Religious exit as a psychological phenomenon has sparsely been researched, and is thus poorly understood. The past research literature has only considered associations of former religious membership with regards to mental health, and has not considered individual factors pre-religious exit. This study examined individual variables of religious exit in the form of the forces influencing and motivating the individual to leave their religious group, using an established migration paradigm. Our findings demonstrate that the migration paradigm of Push and Pull can be applied to those who have left/switched religious groups, and is most salient for those who have left insular religious groups. Further, our findings indicate that an understanding of the pre-religious exit factors of Push and Pull may elucidate the individual experiences of religious leavers and may also be helpful in predicting mental health outcomes. 


\section{References}

Altemeyer, B., \& Hunsberger, B. (1997). Amazing conversions: Why some turn to faith and others abandon religion. Amherst, NY: Prometheus Books.

Arce, D. G., \& Sandler, T. (2009). Fitting in: Group effects and the evolution of fundamentalism. Journal of Policy Modeling, 31(5), 739-757.

Pew Research Center (2015). America's changing religious landscape. Retrieved from http://www.pewforum.org/2015/05/12/americas-changing-religious-landscape/

Anderton, C. L., Pender, D. A., \& Asner-Self, K. K. (2011). A review of the religious identity/sexual orientation identity conflict literature: Revisiting Festinger's cognitive dissonance theory. Journal of LGBT Issues in Counseling, 5(3-4), 259-281.

American Psychiatric Association. (2013). DSM-5 Self-Rated Level 1 Cross-Cutting Symptom Measure-Adult. Retrieved from https://www.psychiatry.org/psychiatrists/practice/dsm/educational-resources/assessmentmeasures.

Amit, K. (2010). Determinants of life satisfaction among immigrants from Western countries and from the FSU in Israel. Social Indicators Research, 96(3), 515-534.

Bahr, H. M. (1970). Aging and religious disaffiliation. Social Forces, 49(1), 59-71.

Bahr, H. M., \& Albrecht, S. L. (1989). Strangers once more: Patterns of disaffiliation from Mormonism. Journal for the Scientific Study of Religion, 180-200.

Baker, J. O. B., \& Smith, B. (2009). None too simple: Examining issues of religious nonbelief and nonbelonging in the United States. Journal for the Scientific Study of Religion, 48(4), $719-733$. 
Bansal, H. S., Taylor, S. F., \& James, Y. S. (2005). "Migrating” to new service providers: Toward a unifying framework of consumers' switching behaviors. Journal of the Academy of Marketing Science, 33(1), 96-115.

Berger, R. (2014). Leaving an Insular Community: The case of Ultra Orthodox Jews. Jewish Journal of Sociology, 56(1/2), 75-98.

Blaine, B., \& Crocker, J. (1995). Religiousness, race, and psychological well-being: Exploring social psychological mediators. Personality and Social Psychology Bulletin, 21(10), 1031-1041.

Brent, J. S. (1994). Leaving Protestant fundamentalism: A qualitative analysis of a major life transition. Counseling and Values, 38(3), 205-214.

Brinkerhoff, M. B., \& Burke, K. L. (1980). Disaffiliation: Some notes on "Falling from the Faith". Sociological Analysis, 41(1), 41-54.

Brinkerhoff, M. B., \& Mackie, M. M. (1993). Casting off the bonds of organized religion: A religious-careers approach to the study of apostasy. Review of Religious Research, 235258.

Bromley, D. G. (1998). Linking social structure and the exit process in religious organizations: Defectors, whistle-blowers, and apostates. Journal for the Scientific Study of Religion, $145-160$.

Chan, D. (2009). So why ask me? Are self-report data really that bad? In Statistical and methodological myths and urban legends: Doctrine, verity and fable in the organizational and social sciences (pp. 309-336). New York, NY, US: Routledge/Taylor \& Francis Group.

Chang, I. C., Liu, C. C., \& Chen, K. (2014). The push, pull and mooring effects in virtual migration for social networking sites. Information Systems Journal, 24(4), 323-346. 
Clarke, D. E., \& Kuhl, E. A. (2014). DSM-5 cross-cutting symptom measures: a step towards the future of psychiatric care? World Psychiatry, 13(3), 314-316.

Davidman, L. (2014). Becoming un-Orthodox: Stories of ex-Hasidic Jews. New York, NY: Oxford University Press.

Diener, E., Emmons, R. A., Larsen, R. J., \& Griffin, S. (1985). The satisfaction with life scale. Journal of Personality Assessment, 49(1), 71-75.

Doerschler, P. (2006). Push-Pull Factors and Immigrant Political Integration in Germany. Social Science Quarterly, 87(5), 1100-1116.

Ebaugh, H. R. F. (1988). Becoming an ex: The process of role exit. Chicago, IL: University of Chicago Press.

Ellison, C. G. (1991). Religious involvement and subjective well-being. Journal of Health and Social Behavior, 80-99.

Engelman J., Milstein, G., Schonfeld I. S., \& Grubbs, J. B. (2020). Leaving a covenantal religion: Orthodox Jewish disaffiliation from an immigration psychology perspective. Mental Health, Religion \& Culture, 23(2), 153-172. doi:

$10.1080 / 13674676.2020 .1744547$

Fenelon, A., \& Danielsen, S. (2016). Leaving my religion: Understanding the relationship between religious disaffiliation, health, and well-being. Social Science Research, 57, 4962.

Fisher, A. R. (2017). A review and conceptual model of the research on doubt, disaffiliation, and related religious changes. Psychology of Religion and Spirituality, 9(4), 358.

Hadaway, C. K., \& Marler, P. L. (1993). All in the family: Religious mobility in America. Review of Religious Research, 35(2), 97-116. 
Hoge, R., Johnson, B., \& Luidens, D. A. (1995). Types of denominational switching among Protestant young adults. Journal for the Scientific Study of Religion, 34(2), 253-258.

Hookway, N. S., \& Habibis, D. (2015). 'Losing my religion': Managing identity in a postJehovah's Witness world. Journal of Sociology, 51(4), 843-856.

Hout, M., \& Fischer, C. S. (2014). Explaining Why More Americans Have No Religious Preference: Political Backlash and Generational Succession, 1987-2012. Sociological Science, 1, 423-447.

Hui, C. H., Cheung, S.-H., Lam, J., Lau, E. Y. Y., Cheung, S.-F., \& Yuliawati, L. (2018). Psychological changes during faith exit: A three-year prospective study. Psychology of Religion and Spirituality, 10(2), 103-118.

Hunsberger, B. E. (1983). Apostasy: A social learning perspective. Review of Religious Research, 25(1), 21-38.

Jackson, J. A. (1986). Migration-Aspects of modern sociology. London: Longman.

Klein, D., Hofmeister, M., Lockyer, J., Crutcher, R., \& Fidler, H. (2009). Push, Pull, and Plant: The Personal Side of Physician Immigration to Alberta, Canada. Family Medicine, 41(3), 197-201.

LeDrew, S. (2013). Discovering atheism: Heterogeneity in trajectories to atheist identity and activism. Sociology of Religion, 74(4), 431-453.

Longino Jr, C. F. (1992). The forest and the trees: micro-level considerations in the study of geographic mobility in old age. In Rogers, A. (Ed.), Elderly Migration and Population Redistribution (pp. 23-34). London: Belhaven.

Maples-Keller, J. L., Williamson, R. L., Sleep, C. E., Carter, N. T., Campbell, W. K., \& Miller, J. D. (2017). Using item response theory to develop a 60-item representation of the NEO 
PI-R using the International Personality Item Pool: Development of the IPIP-NEO-60. Journal of Personality Assessment, 1-12.

McGinnis, C. Z. (2015). Family ostracism in Christianity and counseling. Journal of Psychology and Christianity, 34(1), 79.

Moon, B. (1995). Paradigms in migration research: exploring" moorings" as a schema. Progress in Human Geography, 19(4), 504-524.

Park, C. L. (2005). Religion as a meaning-making framework in coping with life stress. Journal of Social Issues, 61(4), 707-729.

Pavot, W., \& Diener, E. (1993). Review of the satisfaction with life scale. Psychological Assessment, 5(2), 164.

Pavot, W., Diener, E., Colvin, C. R., \& Sandvik, E. (1991). Further validation of the Satisfaction with Life Scale: Evidence for the cross-method convergence of well-being measures. Journal of Personality Assessment, 57(1), 149-161.

Rauhut, D. (2011). On push and pull factors: women's immigration to Sweden from Finland, Norway, and West Germany, 1945-60. Scandia, 77(1), 104-133.

Scheitle, C. P., \& Adamczyk, A. (2010). High-cost religion, religious switching, and health. Journal of Health and Social Behavior, 51(3), 325-342.

Sherkat, D. E., \& Wilson, J. (1995). Preferences, constraints, and choices in religious markets: An examination of religious switching and apostasy. Social Forces, 73(3), 993-1026.

Stark, R., \& Glock, C. Y. (1970). American piety: The nature of religious commitment. Berkley, CA: University of California Press.

Steger, M. F. (2004). Development and validation of the Meaning in Life Questionnaire: A measure of eudaimonic well-being (Doctoral dissertation, University of Minnesota). 
Steger, M. F., Pickering, N. K., Adams, E., Burnett, J., Shin, J. Y., Dik, B. J., \& Stauner, N. (2010). The quest for meaning: Religious affiliation differences in the correlates of religious quest and search for meaning in life. Psychology of Religion and Spirituality, 2(4), 206-226.

Sullivan, A. R. (2010). Mortality differentials and religion in the United States: Religious affiliation and attendance. Journal for the Scientific Study of Religion, 49(4), 740-753.

Twenge, J. M., Sherman, R. A., Exline, J. J., \& Grubbs, J. B. (2016). Declines in American adults' religious participation and beliefs, 1972-2014. Sage Open, 6(1). doi:10.1177/2158244016638133.

Wilson, J., \& Sherkat, D. E. (1994). Returning to the fold. Journal for the Scientific Study of Religion, 33(2), 148-161. 
Table 1

Demographics of Participants

\begin{tabular}{|c|c|c|}
\hline \multirow[b]{2}{*}{ Item } & \multicolumn{2}{|c|}{$n=842$} \\
\hline & $\%$ & Mean $(S D)$ \\
\hline Age & & $37.72(12.19)$ \\
\hline Years since disaffiliation/religious switch & & $9.92(9.83)$ \\
\hline \multicolumn{3}{|l|}{ Gender } \\
\hline Female & $57.5 \%$ & \\
\hline Male & $37.8 \%$ & \\
\hline Another/Decline & $4.7 \%$ & \\
\hline \multicolumn{3}{|l|}{ Ethnicity (select all that apply) } \\
\hline White/Caucasian & $90.2 \%$ & \\
\hline Latinx/Hispanic & $3.8 \%$ & \\
\hline Asian/Pacific Islander & $2.9 \%$ & \\
\hline American Indian/Native American & $2.1 \%$ & \\
\hline Middle Eastern & $2.0 \%$ & \\
\hline African American/Black & $1.6 \%$ & \\
\hline Another/Prefer not to say & $3.3 \%$ & \\
\hline \multicolumn{3}{|l|}{ Relationship Status (select all that apply) } \\
\hline In a committed relationship & $60.9 \%$ & \\
\hline Single & $22.4 \%$ & \\
\hline Divorced & $6.4 \%$ & \\
\hline Separated & $2.7 \%$ & \\
\hline Widowed & $0.9 \%$ & \\
\hline Prefer not to say & $0.6 \%$ & \\
\hline \multicolumn{3}{|l|}{ Sexual Orientation } \\
\hline Heterosexual & $71.1 \%$ & \\
\hline Bisexual & $12.6 \%$ & \\
\hline Homosexual & $7.1 \%$ & \\
\hline Pansexual & $3.9 \%$ & \\
\hline Asexual & $2.8 \%$ & \\
\hline Another/prefer not to say & $2.6 \%$ & \\
\hline \multicolumn{3}{|l|}{ Born in the United States } \\
\hline Yes & $77.1 \%$ & \\
\hline \multicolumn{3}{|l|}{ Highest Level of Education Completed } \\
\hline College graduate & $31.4 \%$ & \\
\hline Master's degree & $19.3 \%$ & \\
\hline Some college & $18.5 \%$ & \\
\hline High School & $10.0 \%$ & \\
\hline 2-year degree & $8.0 \%$ & \\
\hline Professional degree & $5.9 \%$ & \\
\hline Doctoral degree & $5.5 \%$ & \\
\hline Elementary School & $0.7 \%$ & \\
\hline \multicolumn{3}{|l|}{ Religious Denomination Origin Group } \\
\hline Evangelical Christian & $30.5 \%$ & \\
\hline Jehovah's Witness & $18.6 \%$ & \\
\hline
\end{tabular}


Church of Latter-Day Saints

$15.6 \%$

Catholic Christian

$8.4 \%$

Mainline Christian

$7.6 \%$

Orthodox Jewish

$6.6 \%$

Another

$12.7 \%$

Current Religious Status

Disaffiliated from religion

$78.1 \%$

Switched religions

$18.9 \%$

Did not specify

$2.9 \%$

Frequency of religious switching/disaffiliation

Once

$79.3 \%$

Multiple times

$20.7 \%$ 
Table 2

Descriptive Statistics for Included Variables

\begin{tabular}{lccccc}
\hline & $\underline{\mathrm{N}}$ & Observed Range & $\underline{\mathrm{M}}$ & $\underline{\mathrm{SD}}$ & $\underline{\alpha}$ \\
\cline { 2 - 6 } Life Satisfaction & 847 & $5.00-35.00$ & 22.15 & 7.07 & .88 \\
Presence of Life Meaning & 844 & $5.00-35.00$ & 23.22 & 6.86 & .90 \\
Former Group Insularity & 825 & $1.00-4.71$ & 2.53 & .80 & .86 \\
Continued Involvement & 850 & $0.00-7.00$ & 1.49 & 1.11 & .73 \\
Cost of Disaffiliation & 837 & $1.00-6.00$ & 3.25 & 1.18 & .84 \\
Religious Salience & 824 & $0.00-10.00$ & 2.30 & 3.39 & .97 \\
Push & 850 & $1.00-7.00$ & 3.49 & 1.60 & .74 \\
Pull & 843 & $1.00-7.00$ & 3.98 & 1.44 & .67 \\
DSM Composite & 850 & $0.00-4.00$ & 1.40 & 1.01 & .89 \\
Neuroticism & 834 & $1.08-5.00$ & 2.94 & .76 & .84 \\
\hline
\end{tabular}


Table 3

Latent Path Loadings and Descriptive Statistics for Final Push Pull Items

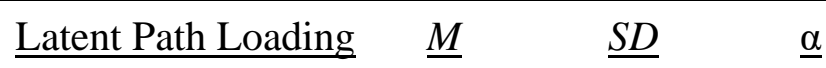

Push

1. I wanted to leave my religious community to get

.745

4.85

2.16

away from dysfunctional surroundings.

2. I experienced physical harm while in my religious community.

3. I wanted to leave my religious community because I

.722

3.56 was shamed by others within the community.

4. I was pushed out by forces within from my former religious community.

Pull

1. When I was within my former religious community

it seemed that it would be an easier life to not live that way.

2. I was drawn outside of my former religious community so that I could lead my own life, instead of following what I was told to do.

3. I wanted to leave my former religious community so that I could dress to my liking.

4. I was motivated to leave my community by others .395 2.90 1.95 who had left before me.

Note. All coefficients, $p<.001$. The fit for this latent variable model is as follows: $\chi^{2}(19)=$ $73.262, p<.001$, comparative fit index $(\mathrm{CFI})=.991$, root mean square error of approximation $($ RMSEA $)=.040$, standardized root mean square residual $(\mathrm{SRMR})=.035$. 
Table 4

Pearson Product Moment Correlations of the Independent and Dependent Variables

\begin{tabular}{|c|c|c|c|c|c|c|c|c|c|c|}
\hline & 1. & 2. & 3. & 4. & 5. & 6. & 7. & 8. & 9. & 10. \\
\hline 1. Life Satisfaction & -- & & & & & & & & & \\
\hline 2. Life Meaning & $.51^{* *}$ & -- & & & & & & & & \\
\hline 3. Insularity & $-.10^{* *}$ & -.07 & -- & & & & & & & \\
\hline 4. Cost of Leaving & -.05 & -.03 & $.62^{* *}$ & -- & & & & & & \\
\hline 5. Neuroticism & $-.42^{* *}$ & $-.38^{* *}$ & $.09^{*}$ & .07 & -- & & & & & \\
\hline 6. Continued Involvement & $-.08^{*}$ & .00 & $.07^{*}$ & -.02 & -.02 & -- & & & & \\
\hline 7. Religious Salience & .02 & $.12^{* *}$ & -.07 & -.05 & .02 & .06 & -- & & & \\
\hline 8. Push & $-.11^{* *}$ & -.05 & $.43^{* *}$ & $.50^{* *}$ & $.24^{* *}$ & $-.10^{* *}$ & .05 & -- & & \\
\hline 9. Pull & -.05 & -.04 & $.44^{* *}$ & $.41^{* *}$ & $.19^{* *}$ & -.01 & -.01 & $.54^{* *}$ & -- & \\
\hline 10. DSM Composite & $-.52^{* *}$ & $-.42^{* *}$ & $.10^{* *}$ & $.08^{*}$ & $.63^{* *}$ & .05 & .06 & $.27^{* *}$ & $.18^{* *}$ & -- \\
\hline 11. Time Since Leaving & $.15^{* *}$ & $.16^{* *}$ & $-.13^{* *}$ & $-.10^{* *}$ & $-.10^{* *}$ & $-.29^{* *}$ & -.07 & $-.07^{*}$ & $-.16^{* *}$ & $-.13^{* *}$ \\
\hline
\end{tabular}

Note. ${ }^{*} p<.05,{ }^{* * *} p<.001$. 
Figure 1

Structural Equation Model Predicting Reduced Mental Health

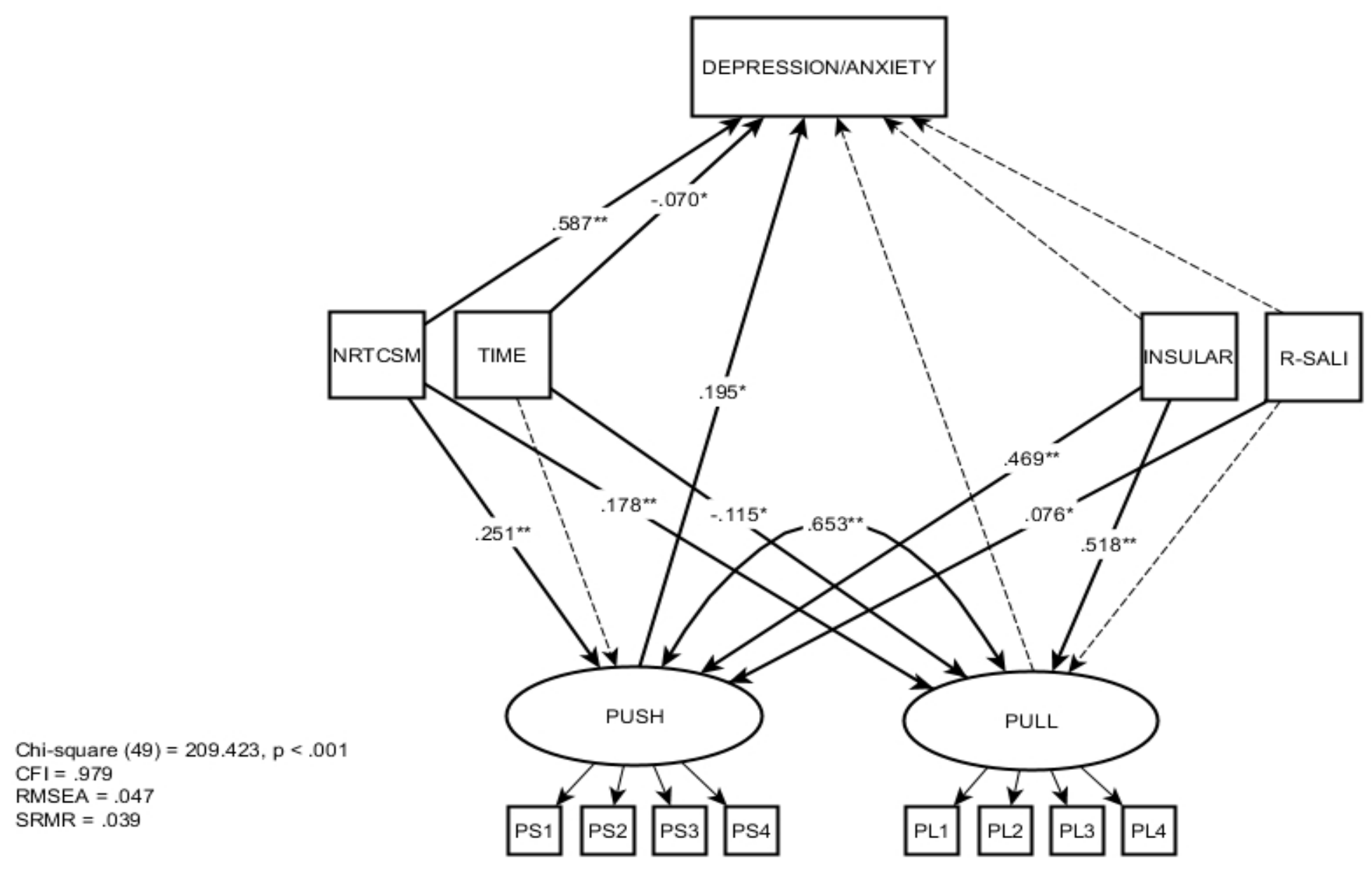

Note. ${ }^{*} p<.05,{ }^{* *} p<.001$. Coefficients for nonsignificant items omitted from diagram to enhance readability. 
Figure 2

Structural Equation Model Predicting Psychological Adjustment

Chi-square $(55)=202.666, p<.001$ $\mathrm{CFI}=.979$

RMSEA $=.043$

$\mathrm{SRMR}=.037$

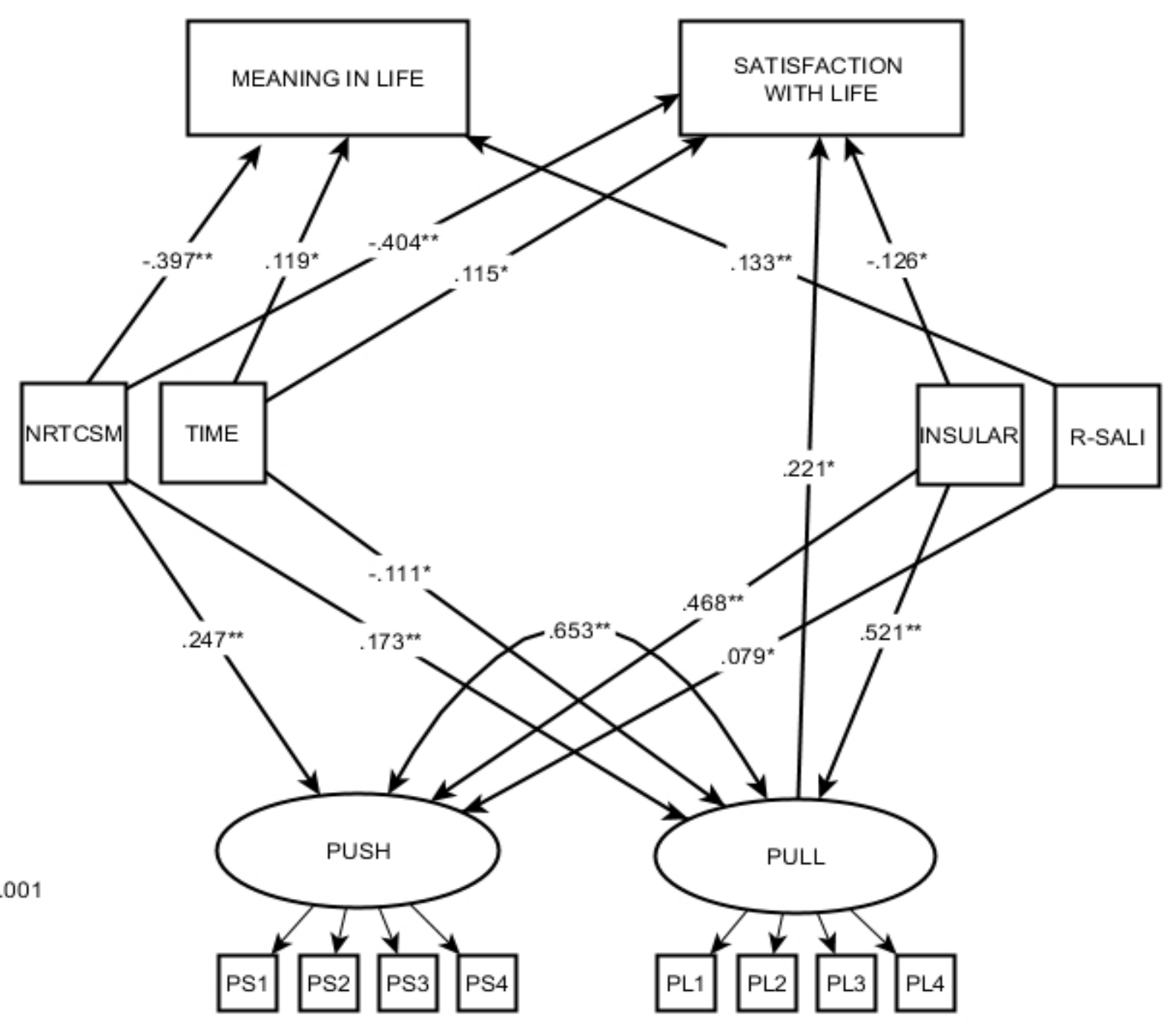

Note. ${ }^{*} p<.05,{ }^{* *} p<.001$. Paths and coefficients for nonsignificant items omitted from diagram to enhance readability. 